\title{
Comparative Study between 2D and 3D Modeling of Nanofluid Filled Flat Plate Solar Collector
}

\author{
R. Nasrin ${ }^{1 *}$, M. A. Alim ${ }^{1}$ and S. R. Ahmed ${ }^{2}$ \\ ${ }^{1}$ Department of Mathematics, Bangladesh University of Engineering and Technology, Dhaka - \\ 1000, Bangladesh \\ ${ }^{2}$ Department of Mechanical Engineering, Bangladesh University of Engineering and Technology, \\ Dhaka - 1000, Bangladesh \\ Email: raity11@gmail.com
}

\begin{abstract}
An attempt is being paid in this paper to numerically analyze the solar thermal collector for better understanding of the heat transfer capabilities of the collector using water as well as water based $\mathrm{Cu}$ nanofluid. In the present work 2D and 3D models of the flat plate solar collector (FPSC) are taken into account. Finite Element method is used to solve governing equations with appropriate boundary conditions. Code validation of numerical study is shown in this article. Heat transfer and flow characteristics are presented in terms of the average heat transfer, mean velocity, collector efficiency and mean outlet temperature of fluids. Then various comparisons are shown to establish the importance of 3D numerical study instead of 2D study.
\end{abstract}

Keywords: 2D and 3D numerical study, Flat plate solar collector, Finite element method, Nanofluid, Collector efficiency.

\section{INTRODUCTION}

Solar energy technologies include solar heating, solar photovoltaic, solar thermal electricity and solar architecture, which can make considerable contributions to solving some of the most urgent problems the world now faces. Because of the desirable environmental and safety aspects it is widely believed that solar energy should be utilized instead of other alternative energy forms, even when the costs involved are slightly higher. Solar flat plate collectors are commonly used for domestic and industrial purposes and have the largest commercial application amongst the various solar collectors. This is mainly due to simple design as well as low maintenance cost.

Conventional analysis and design of solar collector is based on conduction, convection and radiation formulation with natural, forced and mixed convective heat transfer. The absorptance of the collector surface for shortwave solar radiation depends on the nature and color of the coating and on the incident angle. Usually black color is used. The principal requirement of the solar collector is a large contact area between the absorbing surface and the air [1-4].

Two dimensional numerical analyses of solar collector are also performed. The governing equations are discretized on uniform or non-uniform mesh and the discretized equations are then solved with using various methods. Rate of heat transfer and thermal efficiency are obtained for various pertinent parameters [5-11].
The novel approach is to introduce the nanofluids in solar water heater instead of conventional heat transfer fluids (like water). The poor heat transfer properties of these conventional fluids compared to most solids are the primary obstacle to the high compactness and effectiveness of the system. The essential initiative is to seek the solid particles having thermal conductivity of several hundred times higher than those of conventional fluids. These early studies, however, used suspensions of millimeter- or micrometersized particles, which, although showed some enhancement, experienced problems such as poor suspension stability and hence channel clogging, which are particularly serious for systems using mini sized and micro sized particles. The suspended metallic or nonmetallic nanoparticles change the transport properties and heat transfer characteristics of the base fluid [12-16].

Project or survey reports are also conducted on various types of solar collectors [17-21]. Experimental studies are performed based on solar collectors [22-24].

Three dimensional numerical simulation are carried on solar collectors using various techniques. 3D model of the collector involving the water pipe, absorber plate, the glass top and the air gap in-between the absorber plate and the glass top is modeled to provide for conduction, convection and radiation. 3D conjugate heat transfers through unglazed, glazed and gas-filled solar flat plate collectors with and without finned tubes are also investigated [25-31]. 
There is a large scope to work 3D numerical investigation of heat transfer through FPSC using nanofluid. Accurate and reliable three dimensional numerical study is very much required to monitor the variation of collector efficiency, heat transfer system with economic and environmental considerations due to using nanofluids in forced convection mode, which forms the basis of the motivation behind selecting the present work.

\section{GEOMETRICAL MODELING}

The temperature distribution of absorber plate has a symmetry form on each riser pipe. Thus one riser pipe is considered for numerical simulation. A schematic diagram of the system considered in the present study is shown in figure 1.

The nanoparticles are generally spherical shaped and diameter is taken as $10 \mathrm{~nm}$. The nanofluid is considered as single phase laminar flow and surfactant analysis is neglected. The glass top surface is exposed to solar irradiation. It is made up of borosilicate which has thermal conductivity of $1.14 \mathrm{~W} / \mathrm{mK}$ and refractive index of 1.47 , specific heat of 750 $\mathrm{J} / \mathrm{kgK}$ and coefficient of sunlight transmission of $95 \%$. The wavelength of visible light is roughly $0.7 \mu \mathrm{m}$. Thickness of glass cover is $0.005 \mathrm{~m}$. There is an air gap of $0.005 \mathrm{~m}$ between glass cover and absorber plate. Length, width and thickness of the absorber plate are $1 \mathrm{~m}, 0.15 \mathrm{~m}$ and $0.0005 \mathrm{~m}$ respectively. The riser pipe has inner diameter $0.01 \mathrm{~m}$ and thickness $0.0005 \mathrm{~m}$. Coefficients of heat absorption and emmision of copper absorber are $95 \%$ and $5 \%$ respectively. A trapezium shaped bonding conductance of copper metal is located from middle one-third part of width of the absorber plate. It covers the three-fourth part of the riser pipe. It is as long as the absorber plate and tube.

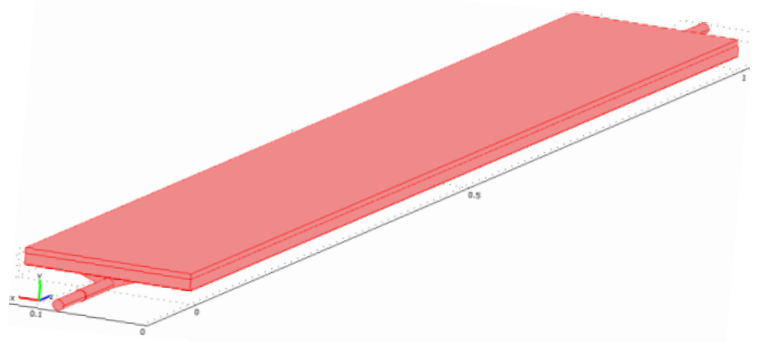

Figure 1. Schematic diagram of a FPSC

\subsection{Computational Domain}

The computation domain is the copper absorber plate containing a fluid passing copper riser pipe with bonding conductance. The riser pipe is generally ultrasonically welded to the absorber plate. The absorber plate is modeled to provide for conduction, convection and radiation in the analysis. Figure 2 shows the computational domain in 3D view.

\section{MATHEMATICAL MODELING}

Let $I$ be the intensity of solar radiation and $A$ be any surface area, then the amount of energy received by any surface is:

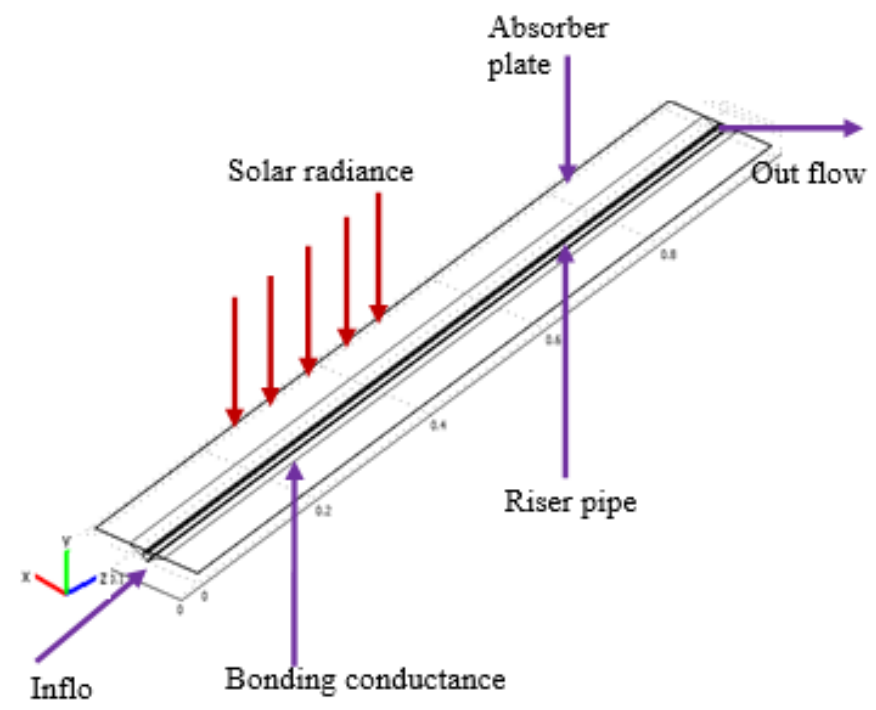

Figure 2. Computational domain of the FPSC

This equation is modified for solar collector surface as it is the product of the rate of transmission of the cover $(\tau)$ and the absorption rate of the absorber $(\alpha)$. Thus,

$Q_{\text {recv }}=I(\tau \alpha) A$

The rate of heat loss $\left(Q_{\text {loss }}\right)$ depends on the collector overall heat transfer coefficient $\left(U_{l}\right)$ and the collector temperature.

$Q_{\text {loss }}=U_{l} A\left(T_{\text {col }}-T_{\text {amb }}\right)$

The rate of useful energy extracted by the collector $\left(Q_{u s f l}\right)$ is:

$$
Q_{u s f l}=Q_{r e c v}-Q_{\text {loss }}=I(\tau \alpha) A-U_{l} A\left(T_{c o l}-T_{a m b}\right)
$$

Rate of heat extraction from the collector can be measured as

$$
Q_{\text {usfl }}=m C_{p}\left(T_{\text {out }}-T_{\text {in }}\right)
$$

where $m, C_{p}, T_{\text {in }}$ and $T_{\text {out }}$ are the mass flow rate per unit area, the specific heat at constant pressure, inlet and outlet fluid temperatures respectively.

The collector heat removal factor relates the actual useful energy gain of a collector to the useful gain if the whole collector surface is at the fluid inlet temperature.

$F_{R}=\frac{m C_{p}\left(T_{o u t}-T_{i n}\right)}{A\left[I(\tau \alpha)-U_{L}\left(T_{i n}-T_{a m b}\right)\right]}$

The actual useful energy gain $\left(Q_{u s f l}\right)$, is found by multiplying the collector heat removal factor $\left(F_{R}\right)$ by the maximum possible useful energy gain. Thus equation (4) can be modified as follows:

$Q_{u s f l}=F_{R} A\left[I(\tau \alpha)-U_{L}\left(T_{i n}-T_{a m b}\right)\right]$ 
The heat flux per unit area of absorber surface $(q)$ is now denoted as

$\frac{Q_{u s f l}}{A}=q=I \tau \alpha-U_{L}\left(T_{i n}-T_{a m b}\right)$

The 3D governing equations are as follows

Continuity equation:

$\frac{\partial u}{\partial x}+\frac{\partial v}{\partial y}+\frac{\partial w}{\partial z}=0$

$x$-momentum equation:

$\rho_{n f}\left(u \frac{\partial u}{\partial x}+v \frac{\partial u}{\partial y}+w \frac{\partial u}{\partial z}\right)=-\frac{\partial p}{\partial x}+\mu_{n f}\left(\frac{\partial^{2} u}{\partial x^{2}}+\frac{\partial^{2} u}{\partial y^{2}}+\frac{\partial^{2} u}{\partial z^{2}}\right)$

y-momentum equation:

$\rho_{n f}\left(u \frac{\partial v}{\partial x}+v \frac{\partial v}{\partial y}+w \frac{\partial v}{\partial z}\right)=-\frac{\partial p}{\partial y}+\mu_{n f}\left(\frac{\partial^{2} v}{\partial x^{2}}+\frac{\partial^{2} v}{\partial y^{2}}+\frac{\partial^{2} v}{\partial z^{2}}\right)$

z-momentum equation:

$\rho_{n f}\left(u \frac{\partial w}{\partial x}+v \frac{\partial w}{\partial y}+w \frac{\partial w}{\partial z}\right)=-\frac{\partial p}{\partial z}+\mu_{n f}\left(\frac{\partial^{2} w}{\partial x^{2}}+\frac{\partial^{2} w}{\partial y^{2}}+\frac{\partial^{2} w}{\partial z^{2}}\right)$

Energy equation for nanofluid:

$u \frac{\partial T}{\partial x}+v \frac{\partial T}{\partial y}+w \frac{\partial T}{\partial z}=\frac{\alpha_{n f}}{\alpha_{f}} \frac{1}{\operatorname{Pr}}\left(\frac{\partial^{2} T}{\partial x^{2}}+\frac{\partial^{2} T}{\partial y^{2}}+\frac{\partial^{2} T}{\partial z^{2}}\right)$

Energy equation for absorber:

$\left(\frac{\partial^{2} T_{a}}{\partial x^{2}}+\frac{\partial^{2} T_{a}}{\partial y^{2}}+\frac{\partial^{2} T_{a}}{\partial z^{2}}\right)=0$

where, $\quad \alpha_{n f}=k_{n f} /\left(\rho C_{p}\right)_{n f}$ is the thermal diffusivity, $\rho_{n f}=(1-\phi) \rho_{f}+\phi \rho_{s} \quad$ is the density, $\left(\rho C_{p}\right)_{n f}=(1-\phi)\left(\rho C_{p}\right)_{f}+\phi\left(\rho C_{p}\right)_{s}$ is the heat capacitance, $\mu_{n f}=\frac{\mu_{f}}{(1-\phi)^{2.5}}$ is the viscosity of Brinkman model [32], $\quad k_{n f}=k_{f} \frac{k_{s}+2 k_{f}-2 \phi\left(k_{f}-k_{s}\right)}{k_{s}+2 k_{f}+\phi\left(k_{f}-k_{s}\right)} \quad$ is the thermal conductivity of Maxwell Garnett (MG) model [33] and $\operatorname{Pr}=\frac{v_{f}}{\alpha_{f}}$ is the Prandtl number.

The boundary conditions of the computation domain are:

1. at all solid boundaries of the riser pipe: $u=v=w=0$

2. at the solid-fluid interface: $k_{f}\left(\frac{\partial T}{\partial N}\right)_{\text {fluid }}=k_{a}\left(\frac{\partial T}{\partial N}\right)_{\text {solid }}$
3. at the inlet boundary of the riser pipe: $T=T_{i n}, w=$ $w_{\text {in }}$

4. at the outlet boundary: convective boundary condition $p=0$

5. at the top surface of the absorber: heat flux $-k_{a} \frac{\partial T_{a}}{\partial z}=q=I \tau \alpha-U_{L}\left(T_{i n}-T_{a m b}\right)$

6. at the other surfaces of absorber plate: $\frac{\partial T_{a}}{\partial N}=0$

7. at the outer boundary of riser pipe: $\frac{\partial T_{a}}{\partial N}=0$

8. at the outer boundary of bonding conductance: $\frac{\partial T_{a}}{\partial N}=0$, where $N$ is the distances either along $x$ or $y$ or $z$ directions acting normal to the surface respectively.

\subsection{Average Nusselt number}

Equation of local Nusselt number for flow through the absorber tube of solar collector can be written as

$$
\overline{N u}=\frac{U_{l} D}{k_{f}}=\frac{Q}{\Delta T}\left(\frac{D}{k_{f}}\right)=\frac{Q}{\left(q D / k_{f}\right)}\left(\frac{D}{k_{f}}\right)
$$

where $D$ is the inner diameter of riser pipe, $\Delta T$ is the difference between riser pipe surface temperature and ambient temperature, $Q$ is the energy received or lost by the absorber pipe surface. For a flat plate solar collector constant heat flux is assigned at the absorber top surface. For water based nanofluid flow this equation becomes

$\overline{N u}=\frac{-k_{n f}\left(\frac{\partial T}{\partial N}\right)}{\left(q D / k_{f}\right)}\left(\frac{D}{k_{f}}\right)=-\left(\frac{k_{n f}}{k_{f}}\right)\left(\frac{k_{f}}{q}\right)\left(\frac{\partial T}{\partial N}\right)$

The normal temperature gradient can be written as

$\frac{\partial T}{\partial N}=\sqrt{\left(\frac{\partial T}{\partial x}\right)^{2}+\left(\frac{\partial T}{\partial y}\right)^{2}+\left(\frac{\partial T}{\partial z}\right)^{2}}$

The non-dimensional form of local heat transfer at the riser pipe solid surface is

$\overline{N u}=-\frac{k_{n f}}{k_{f}} \sqrt{\left(\frac{\partial \theta}{\partial X}\right)^{2}+\left(\frac{\partial \theta}{\partial Y}\right)^{2}+\left(\frac{\partial \theta}{\partial Z}\right)^{2}}$

The above equations are non-dimensionalized by using the following dimensionless quantities

$X=\frac{x}{D}, Y=\frac{y}{D}, Z=\frac{z}{D}, \theta=\frac{\left(T-T_{\text {in }}\right) k_{f}}{q D}$

By integrating the local Nusselt number over the riser pipe, the average heat transfer rate of the collector can be written from Nasrin and Alim [14] 
$N u=\frac{\iint_{S} \overline{N u} d s}{\iint_{s} d S}=-\frac{1}{\pi D L} \frac{k_{n f}}{k_{f}} \iint_{S} \sqrt{\frac{\partial^{2} \theta}{\partial X^{2}}+\frac{\partial^{2} \theta}{\partial Y^{2}}+\frac{\partial^{2} \theta}{\partial Z^{2}}} d s$

where $D$ and $L$ are the diameter and height of absorber tube.

\subsection{Mean velocity}

The sub domain mean velocity of the fluid inside the collector may be written as

$\mathrm{V}_{a v}=\frac{\iiint_{\mathrm{v}} \mathrm{V} d \overline{\mathrm{V}}}{\iiint_{\mathrm{v}} d \overline{\mathrm{V}}}=\frac{4}{\pi D^{2} L} \iiint_{\mathrm{v}} \mathrm{V} d \overline{\mathrm{V}}$

where $\mathrm{V}$ and $\overline{\mathrm{V}}$ are the magnitude of velocity field and volume of the absorber tube respectively.

\subsection{Collector efficiency}

A measure of a flat plate collector performance is the collector efficiency $(\eta)$ defined as the ratio of the useful energy gain $\left(Q_{u s f l}\right)$ to the incident solar energy. The instantaneous thermal efficiency of the collector is:

$$
\begin{aligned}
\eta & =\frac{\text { useful gain }}{\text { available energy }}=\frac{Q_{\text {usfl }}}{A I} \\
& =\frac{F_{R} A\left[I(\tau \alpha)-U_{L}\left(T_{i n}-T_{a m b}\right)\right]}{A I} \\
& =F_{R}(\tau \alpha)-F_{R} U_{L} \frac{\left(T_{i n}-T_{a m b}\right)}{I}
\end{aligned}
$$

\section{COMPUTATIONAL PROCEDURE}

The Galerkin finite element method [34-36] is used to solve the non-dimensional governing equations along with boundary conditions for the considered problem. Conservation equations are solved for the finite element method to yield the velocity and temperature fields for the water flow in the absorber tube and the temperature field for the absorber plate. The convergence of solutions is assumed when the relative error for each variable between consecutive iterations is recorded below the convergence criterion such that $\left|\psi^{n+1}-\psi^{n}\right| \leq 1.0 \mathrm{e}^{-6}$, where $n$ is the number of iteration and $\Psi$ is a function of any one of $u, v, w, T$ and $T_{a}$.

\subsection{Meshing}

It is basically a discrete representation of the geometric domain on which the problem is to be solved. The computational domains with irregular geometries by a collection of finite elements make the method a valuable practical tool for the solution of boundary value problems arising in various fields of engineering. Figure 3 displays the 3D finite element mesh of the present physical domain. Finer mesh size is chosen for this geometry.
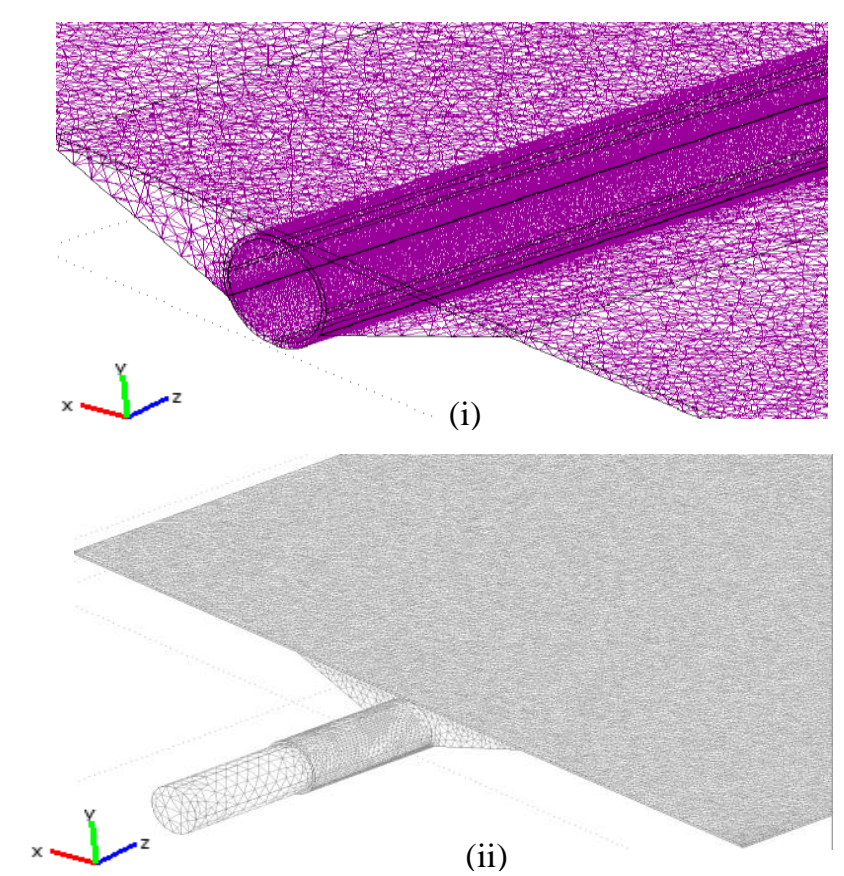

Figure 3. Mesh generation of the collector (i) partial view and (ii) close view of riser pipe

\subsection{Thermo-physical properties}

The thermo-physical properties of the nanofluid are taken from Nasrin and Alim [14] and given in Table 1.

Table 1. Thermo-physical properties of water and $\mathrm{Cu}$ nanoparticle at $300 \mathrm{~K}$

\begin{tabular}{lll}
\hline Physical Properties & Fluid phase (water) & $\mathrm{Cu}$ \\
\hline$C_{p}(\mathrm{~J} / \mathrm{kgK})$ & 4179 & 385 \\
$\rho\left(\mathrm{kg} / \mathrm{m}^{3}\right)$ & 997.0 & 8933 \\
$k\left(\mathrm{~W} / \mathrm{mK}^{3}\right)$ & 0.613 & 400 \\
$\alpha \times 10^{7}\left(\mathrm{~m}^{2} / \mathrm{s}\right)$ & 1.47 & 1163.1 \\
$\mu \times 10^{6}\left(\mathrm{Ns} / \mathrm{m}^{2}\right)$ & 855 & - \\
\hline
\end{tabular}

\subsection{Grid test}

The mesh is composed of tetrahedral element type with ten nodes in subdomain and triangular element size with six nodes in boundaries. The grid independence test is performed to check validity of the quality of mesh on the solution. There is no significant change in $N u$ taking element size 27,04,288 but it is time consuming. This is shown in Table 2. The computation procedure runs taking 14,20,465 elements.

Table 2. Grid Sensitivity Test at $\operatorname{Pr}=5.8, I=215 \mathrm{~W} / \mathrm{m}^{2}, \phi$ $=2 \%$

\begin{tabular}{|l|l|l|l|l|}
\hline Elements & $4,51,098$ & $7,26,222$ & $14,20,465$ & $27,04,288$ \\
\hline $\begin{array}{l}N u \\
\text { (Nanofluid) }\end{array}$ & 2.12154 & 2.28451 & 2.433717 & 2.433807 \\
\hline $\begin{array}{l}\mathrm{Nu} \text { (Base } \\
\text { fluid) }\end{array}$ & 1.89124 & 2.00312 & 2.10124 & 2.10168 \\
\hline Time (s) & 1469.48 & 3846.57 & 78381.18 & 99579.25 \\
\hline
\end{tabular}




\subsection{Code validation}

A comparison of temperature contour plot of absorber plate is shown in figure 4 between the result using present code and Kranath et al. [24]. The numerical study is performed at $I=800 \mathrm{w} / \mathrm{m}^{2}$, inlet velocity $=0.005 \mathrm{~m} / \mathrm{s}$, density $($ copper $)=8900 \mathrm{Kg} / \mathrm{m}^{3}$, specific heat $($ copper $)=385 \mathrm{~J} / \mathrm{kgK}$, viscosity $($ water $)=0.000959 \mathrm{Kg} / \mathrm{ms}$, specific heat (water) $=$ $4179 \mathrm{~J} / \mathrm{kgK}$, thermal conductivity (glass) $=1.14 \mathrm{~W} / \mathrm{mK}$, thermal conductivity (copper) $=387 \mathrm{~W} / \mathrm{mK}$ and thermal conductivity (water) $=0.6 \mathrm{~W} / \mathrm{mK}$. A good agreement is observed from figure 4(present numerical code) and figure 16 (Kranath et al. [24]).

\section{RESULTS AND DISCUSSIONS}

Finite element simulation is applied to observe the thermofluid characteristics through flat plate solar collector where the working fluid water-copper nanofluid as well as water. Effects of solar irradiation $(I)$ and solid volume fraction $(\phi)$ on heat transfer, mean velocity, collector efficiency and mean outlet temperature of fluids have been studied. The ranges of $I$ and $\phi$ for this investigation vary from $200 \mathrm{~W} / \mathrm{m}^{2}$ to $250 \mathrm{~W} / \mathrm{m}^{2}$ and $0 \%$ to $3 \%$ respectively. The outcomes for the different cases using 2D and 3D simulations are presented in the following sections. The considered values of mass flow per unit area $(m)$ is $0.0248 \mathrm{Kg} / \mathrm{s}$, Prandtl number $(\mathrm{Pr})$ is 5.8, input and ambient temperatures of fluid are $300 \mathrm{~K}$ and $298 \mathrm{~K}$, overall heat transfer coefficient $\left(U_{l}\right)$ is $8 \mathrm{~W} / \mathrm{m}^{2} \mathrm{~K}$.

\subsection{D Analysis}

The longitudinal cross section of the FPSC is shown in Figure 5. The absorber plate along with riser pipe is the computational domain. The mesh is displayed in the figure 6.

\subsubsection{Effect of solar irradiation}

The effect of $I$ on the isothermal lines is presented in the figure 7 for $2 \%$ concentrated water-Cu nanofluid. Blue and red colors indicate the lowest and highest temperature respectively. This figure shows that rising solar irradiation accelerates thermal current activities through solar collector. Isotherms are almost similar to the active part of riser pipe. Increasing solar irradiation, the temperature lines at the exit port of the riser pipe become more flatten whereas initially they are bended due to spectral absorption coefficient is dominated across the FPSC. With rising values of $I$ from 200 $\mathrm{W} / \mathrm{m}^{2}$ to $250 \mathrm{~W} / \mathrm{m}^{2}$, the temperature distributions become distorted resulting in an increase in the overall heat transfer. This result can be attributed to the dominance of the absorption coefficient. It is worth noting that as the solar irradiation increases, the thickness of the thermal boundary layer near the output surface expands which indicates a steep temperature gradients and hence, an increase in the overall heat transfer from the hot walls to the fluid through the fluid passing region.

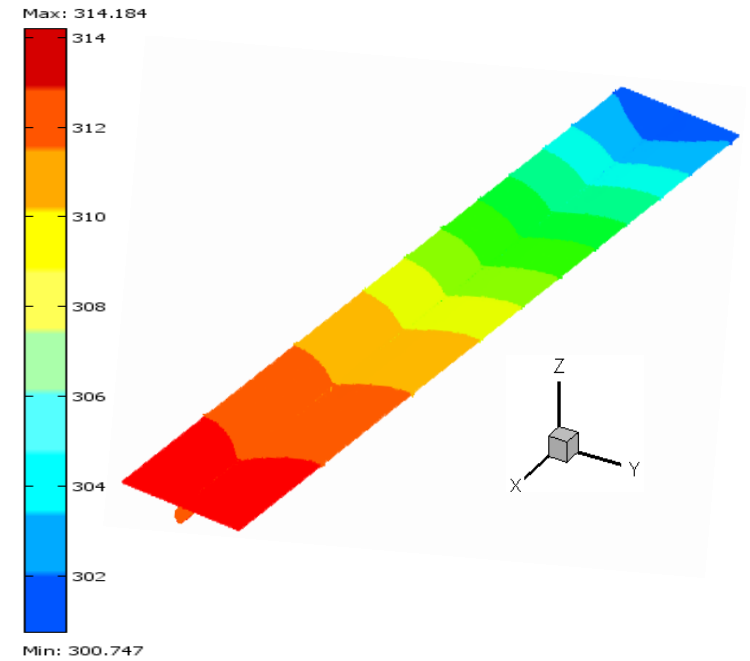

Figure 4. Code validation of temperature contour of absorber plate

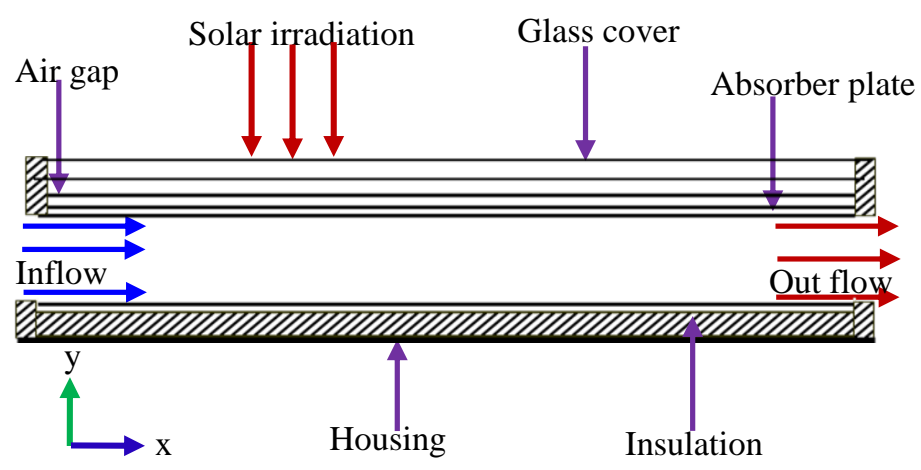

Figure 5. Longitudinal cross-section of a FPSC

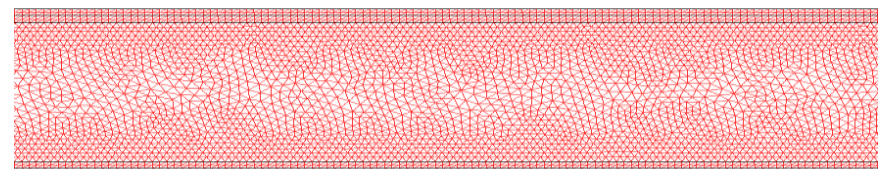

Figure 6. Mesh generation of the 2D domain

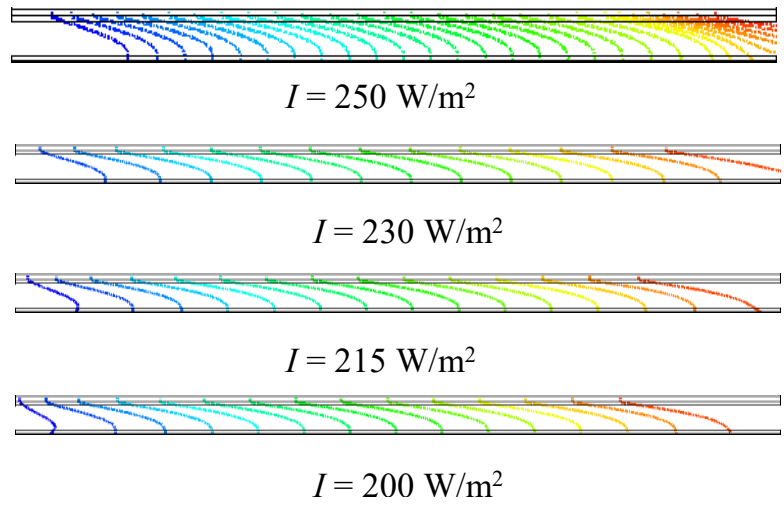

Figure 7. Effect of $I$ on isothermal lines 


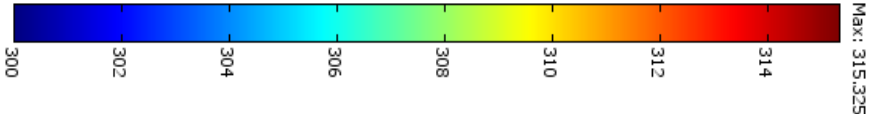

$\phi=3 \%$

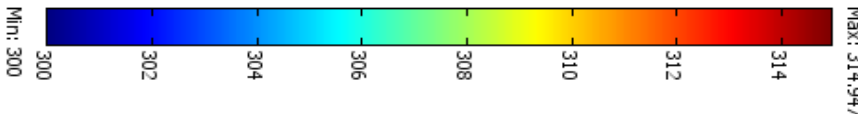

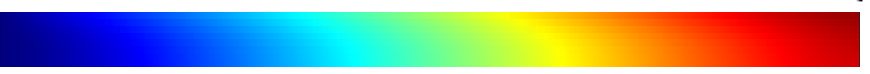

$\phi=2 \%$
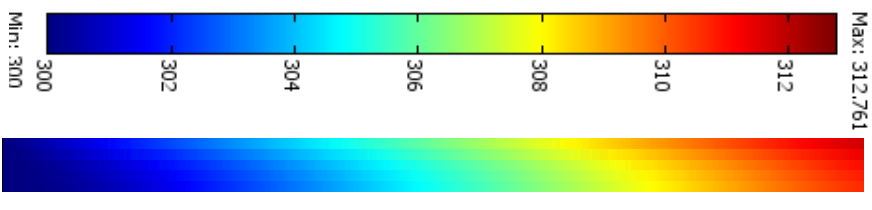

$\phi=1 \%$

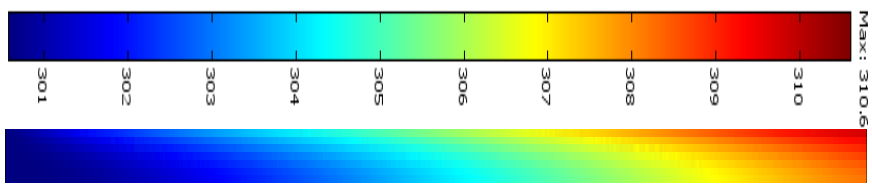

$\phi=0 \%$

Figure 8. Effect of $\phi$ on surface temperature

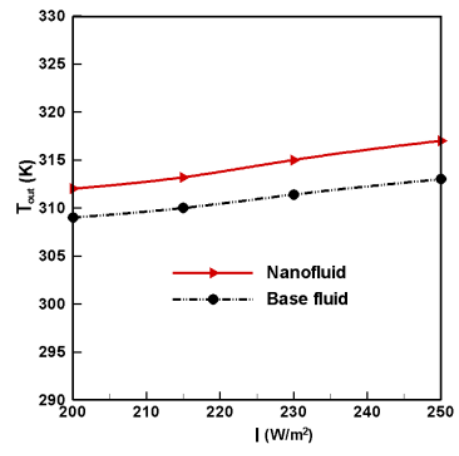

(i)

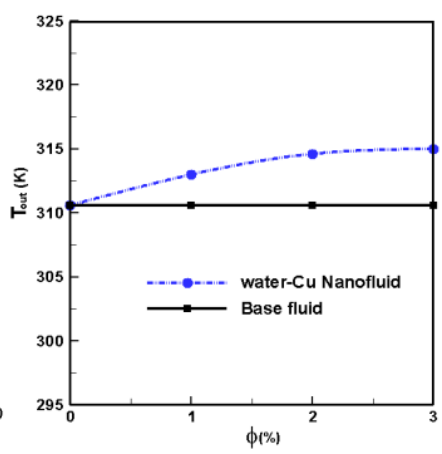

(ii)
Figure 9. Outlet temperature for the variation of (i) / and (ii) $\phi$

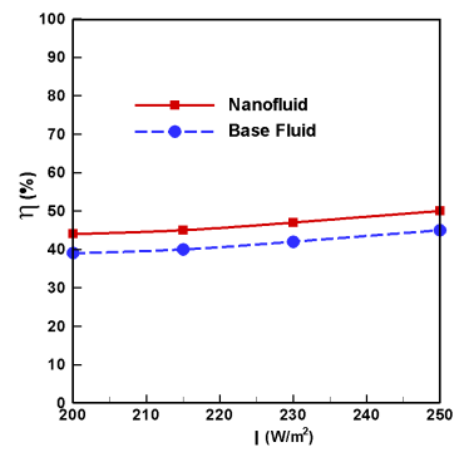

(i)

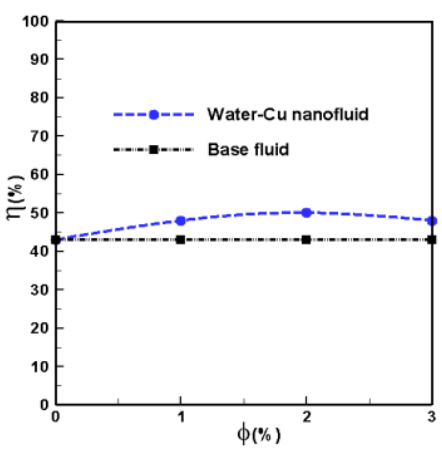

(ii)
Figure 10. Thermal efficiency for the variation of (i) / and (ii) $\phi$

\subsubsection{Effect of solid volume fraction}

Figure 8 represents the surface temperature for different values of solid volume fraction $(\phi=0 \%, 1 \%, 2 \%, 3 \%)$ of $\mathrm{Cu}$ nanoparticles at $I=215 \mathrm{~W} / \mathrm{m}^{2}$. Initially at $\phi=0 \%$ ie. water is heat transfer medium then the absorber temperature is low. Adding nanoparticle with base fluid from $0 \%$ to $3 \%$ the temperature of absorber plate as well as output nanofluid become high gradually. This indicates that the heat flow is conduction dominant due to more thermal conductive heat flux. Major amount of heat flux occurs for presence of copper nanoparticle.

\subsubsection{Outlet temperature}

The effects of solar irradiation $(I)$ and solid concentration $(\phi)$ on outlet mean temperature of fluids are expressed in the figure 9(i)-(ii). Mean output temperature of nanofluid rises from $312 \mathrm{~K}$ to $317 \mathrm{~K}$ for nanofluid and from $309 \mathrm{~K}$ to $313 \mathrm{~K}$ for base fluid with the variation of $I$ from $200 \mathrm{~W} / \mathrm{m}^{2}$ to 250 $\mathrm{W} / \mathrm{m}^{2}$. Similarly outlet mean temperature $(T)$ increases with growing $\phi$. The output temperature of nanofluid increases from $310.6 \mathrm{~K}$ to $315 \mathrm{~K}$ for rising $\phi$ from $0 \%$ to $3 \%$.

\subsubsection{Thermal efficiency}

Figure 10(i)-(ii) expresses the $\eta-I$ and $\eta-\phi$ profiles for copper/water nanofluid as well as clear water through a flat plate solar collector. Greater solar irradiation increases the collector efficiency from $44 \%-50 \%$ for nanofluid and from $39 \%-45 \%$ for water. From the figure 10(ii) it is seen that increasing $\phi$ from $0 \%$ to $2 \%$ rises the percentage of collector efficiency $(\eta)$ from $43 \%-50 \%$. Additional mixing of $\phi$ beyond this level dencreases $\eta$. The phenomena can be attributed as there is a little increment in output temperature at $\phi=3 \%$. But value of specific heat at constant pressure of $3 \%$ concentrated water-Cu nanofluid becomes lower.

\subsection{D Analysis}

The results for three dimensional numerical analysis are described as follows:

\subsubsection{Effect of solar irradiation}

The effect of $I$ on the temperature of slice plot is presented in figure 11 for $2 \%$ concentrated water- $\mathrm{Cu}$ nanofluid. The considered values of solar irradiation are $I\left(=200 \mathrm{~W} / \mathrm{m}^{2}\right.$, $215 \mathrm{~W} / \mathrm{m}^{2}, 230 \mathrm{~W} / \mathrm{m}^{2}$ and $250 \mathrm{~W} / \mathrm{m}^{2}$ ). Different colours of slices indicate different temperatures as shown in the figure. Initially at $I=200 \mathrm{~W} / \mathrm{m}^{2}$, irradiation is low, temperature of nanofluid at the outlet edge is low. The strength of the thermal current activities is much more activated with escalating I. Slices illustrate that solar irradiation dominant effect plays a critical role on larger heat flow from absorber walls to the passing fluid through the riser pipe. In the temperature distribution of slice plot for different values of solar irradiation shows that absorber temperature as well as nanofluid temperature increases with rising values of $I$.

\subsubsection{Effect of solid volume fraction}

Figure 12 represents the temperature of contour plot for different values of solid volume fraction $(\phi=0 \%, 1 \%, 2 \%$, $3 \%$ ) of $\mathrm{Cu}$ nanoparticles at $I=215 \mathrm{~W} / \mathrm{m}^{2}$. Initially at $\phi=0 \%$ ie. water is working fluid then the temperature contour of absorber plate is not high. Mixing nanoparticle with base 
fluid from $0 \%$ to $3 \%$ the temperature of absorber plate as well as output nanofluid become high gradually.
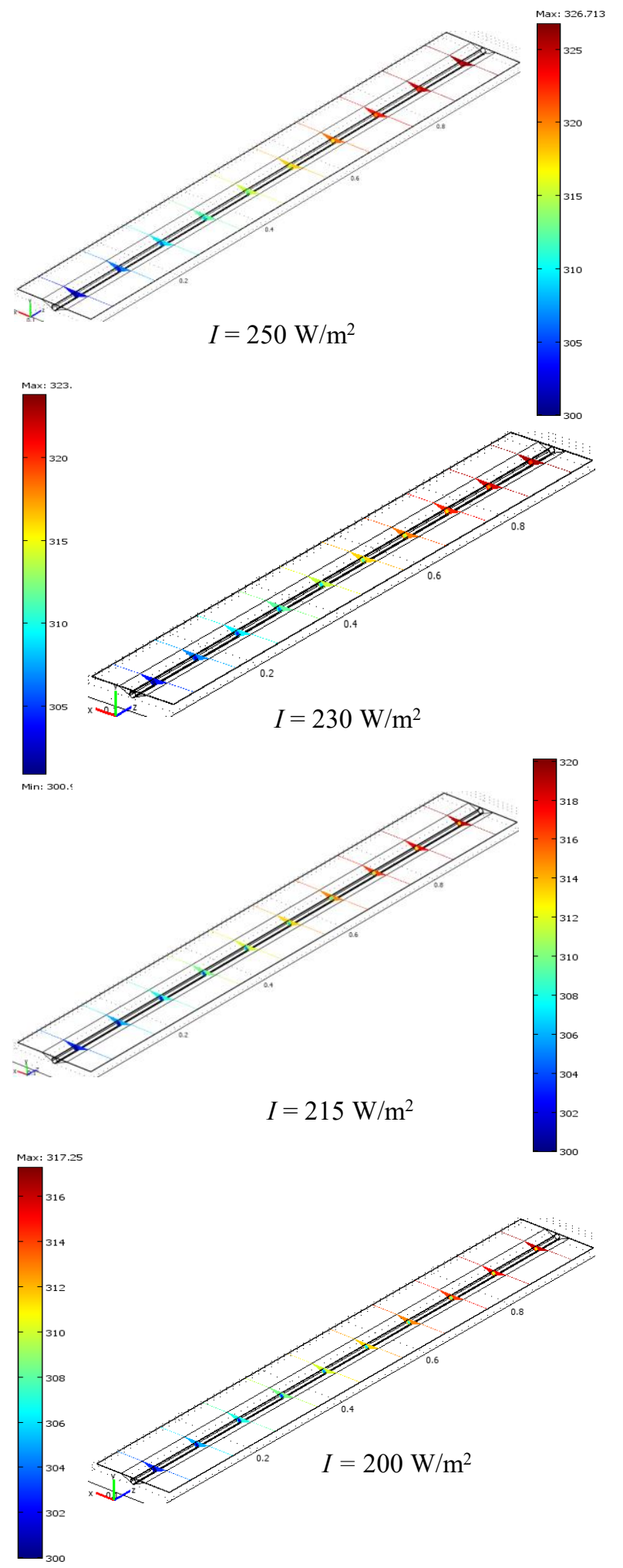

Figure 11. Temperature of slice plot at different $I$

\subsubsection{Rate of heat transfer}

The average Nusselt number along with the various solar irradiation $(I)$ and solid volume fraction $(\phi)$ are displayed in figure 13 (i)-(ii). The rate of forced convective heat transfer enhances $14 \%$ and $10 \%$ using nanofluid and water respectively for rising solar irradiation from $200 \mathrm{~W} / \mathrm{m}^{2}$ to 250 $\mathrm{W} / \mathrm{m}^{2}$. $\mathrm{Nu}$ enhances rapidly with growing $\phi$ from $0 \%$ to $2 \%$.
The rate of heat transfer for water-copper nanofluid is found to be more effective than the clear water due to higher thermal conductivity of solid nanoparticles. For growing solid concentration of $\mathrm{Cu}$ nanoparticle from $0 \%$ to $3 \%$ rate of heat transfer rises $17 \%$.

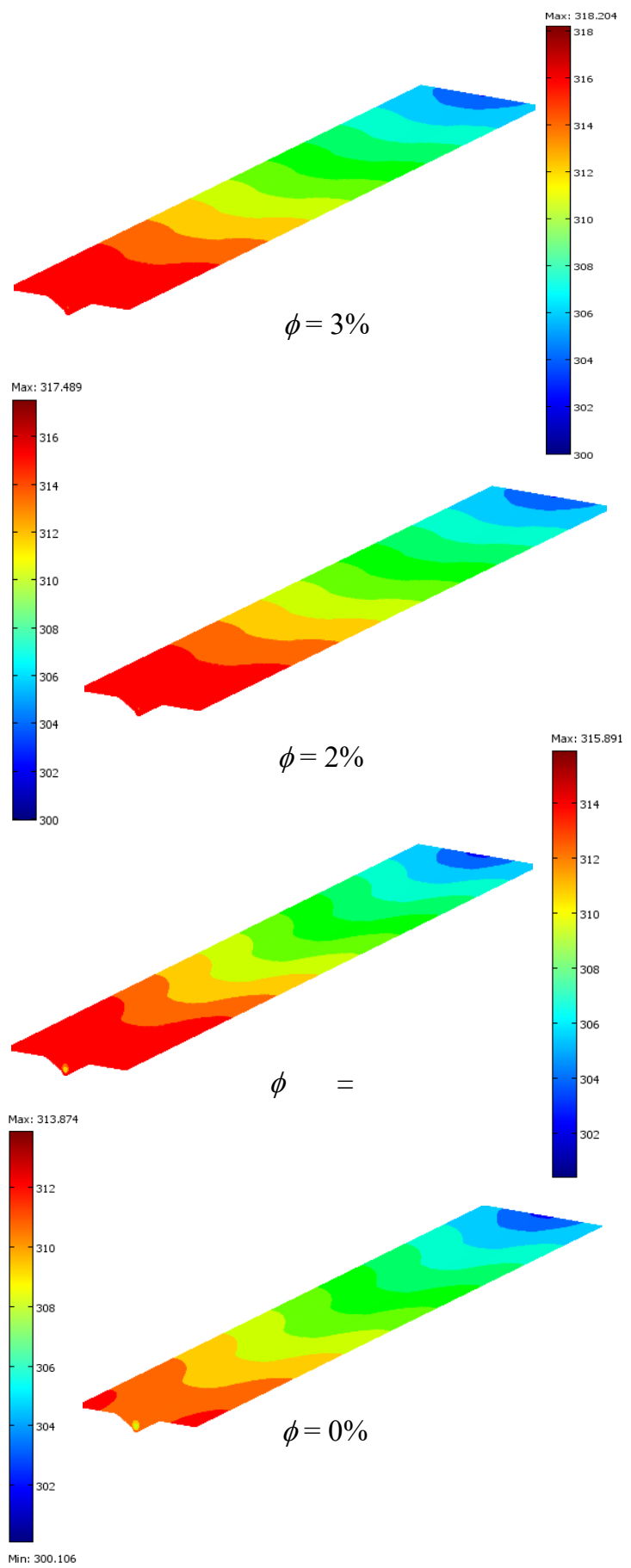

Figure 12. Temperature of contour plot at different $\phi$

\subsubsection{Fluid mean velocity}

The magnitude of average velocity $\left(\mathrm{V}_{\mathrm{av}}\right)$ of fluids versus solar irradiation $(I)$ and solid volume fraction $(\phi)$ are depicted in figure 14(i)-(ii). Sub-domain average velocity of fluids enhances due to increasing solar irradiation. Increasing the radiation, and consequently temperature, the density decreases, and, hence, the mean velocity increases. It is well known that density of nanofluid is higher than water. Clear water moves freely than solid concentrated nanofluid. That's why velocity of clear water is higher than water-Cu nanofluid. 
Average velocity of nanofluid devalues along with the increasing solid volume fraction.

\subsubsection{Outlet temperature}

The effects of solar irradiation $(I)$ and solid concentration $(\phi)$ on outlet mean temperature of fluids are expressed in the figure 15(i)-(ii). The inlet temperature of fluids is maintained at $300 \mathrm{~K}$ and the mean output temperature of nanofluid becomes $314 \mathrm{~K}, 316 \mathrm{~K}, 318 \mathrm{~K}$ and $320 \mathrm{~K}$ for $I=200 \mathrm{~W} / \mathrm{m}^{2}, 215$ $\mathrm{W} / \mathrm{m}^{2}, 230 \mathrm{~W} / \mathrm{m}^{2}$ and $250 \mathrm{~W} / \mathrm{m}^{2}$ respectively. Similarly outlet mean temperature $(T)$ increases with growing $\phi$. The output temperature of nanofluid becomes $312 \mathrm{~K}, 314.5 \mathrm{~K}, 316.3 \mathrm{~K}$ and $316.8 \mathrm{~K}$ for $\phi=0 \%, 1 \%, 2 \%$ and $3 \%$ respectively.

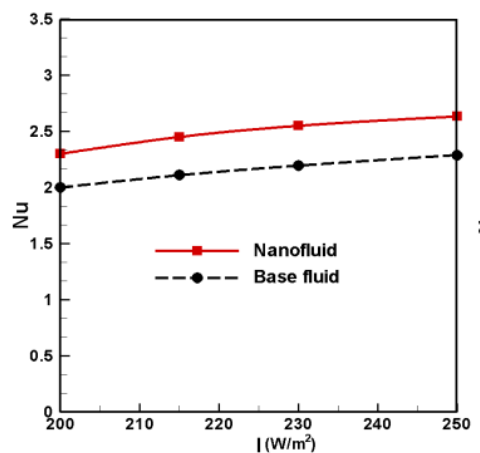

(i)

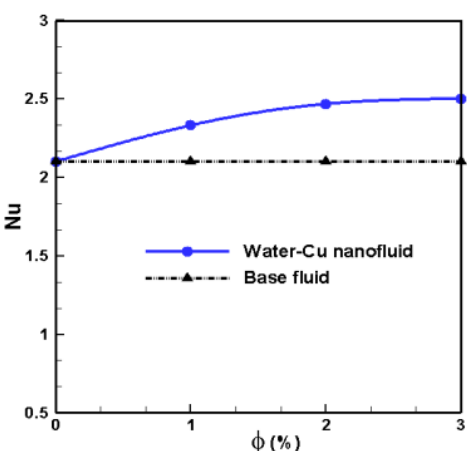

(ii)
Figure 13. Heat transfer rate for the variation of (i) $I$ and (ii) $\phi$

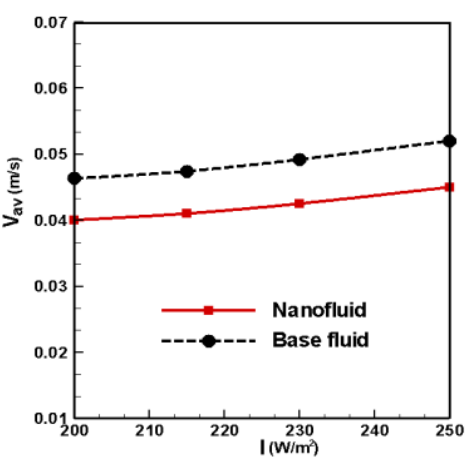

(i)

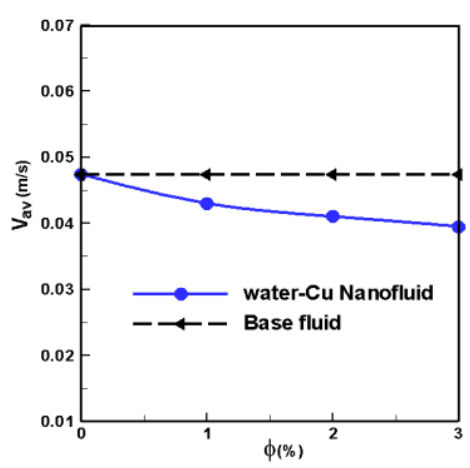

(ii)
Figure 14. Mean velocity for the variation of (i) $I$ and (ii) $\phi$

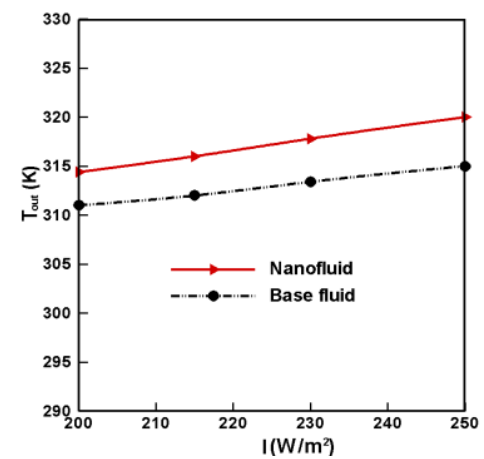

(i)

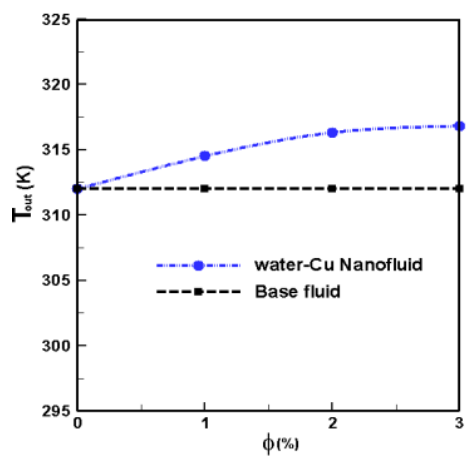

(ii)
Figure 15. Outlet temperature for the variation of (i) $I$ and (ii) $\phi$

\subsubsection{Collector efficiency}

Figure 16(i)-(ii) expresses the $\eta-I$ and $\eta-\phi$ profiles for copper/water nanofluid as well as clear water through a flat plate solar collector. It is observed that by introducing greater solar irradiation the collector efficiency increases from $51 \%$ -
$59 \%$ for nanofluid and from $47 \%-55 \%$ for water. But increasing $\phi$ from $0 \%$ to $2 \%$ rises the percentage of collector efficiency $(\eta)$ from $48 \%-56 \%$. With additional mixing $\phi$ beyond this level doesn't increase $\eta$ but also decrease slightly. It is happened due to lower value of heat capacitance of nanofluid. So increasing solid concentration after a certain level is not advantageous.

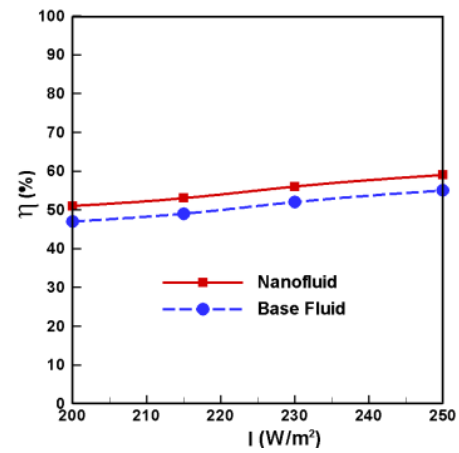

(i)

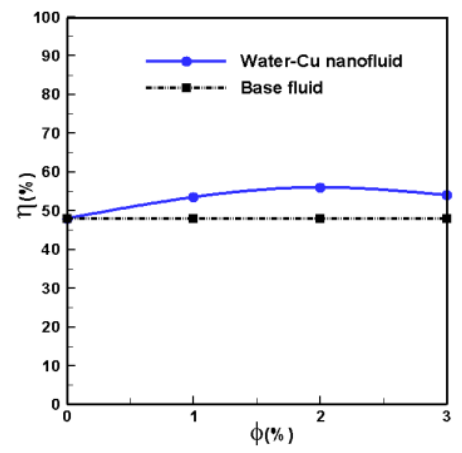

(ii)
Figure 16. Thermal efficiency for the variation of (i) $I$ and (ii) $\phi$

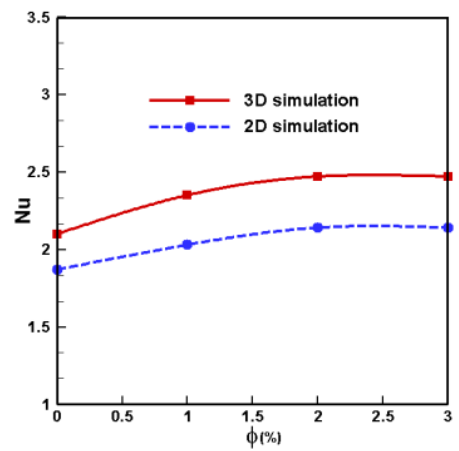

(i)

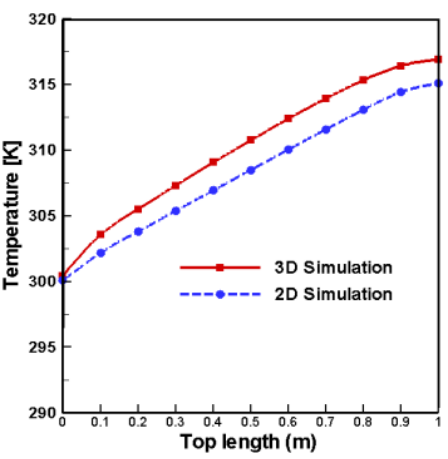

(iii)

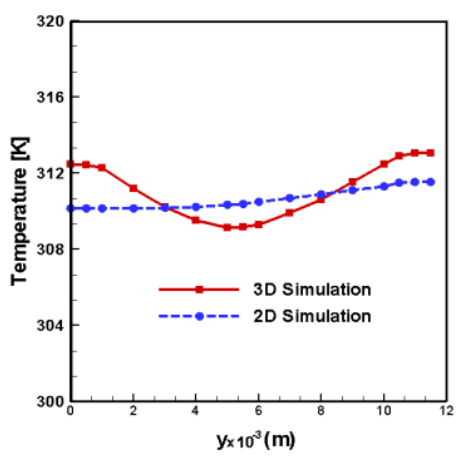

(ii)

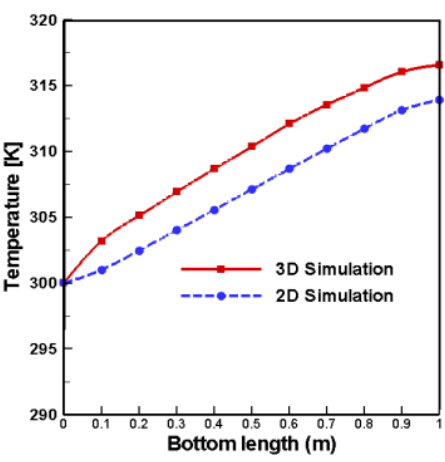

(iv)
Figure 17. Comparison (i) heat transfer rate, (ii) temperature distribution from top to bottom, (iii) along top length and (iv) along bottom length

\section{COMPARISON}

Four comparisons are made between 2D and 3D analyses for a flat plate solar collector at $\operatorname{Pr}=5.8, I=215 \mathrm{~W} / \mathrm{m}^{2}$ and are shown in figure 17 (i)-(iv). Figure 17(i) displays values of heat transfer rate for different values of solid volume fraction of water-Cu nanofluid.

Temperature distribution from top of the absorber plate to the bottom of the riser pipe at the position $0.67 \mathrm{~m}$ of FPSC is 
shown in 17(ii). In the region from top of absorber plate upto centre of fluid, a little bit higher temperature is found for $3 \mathrm{D}$ analysis than that of $2 \mathrm{D}$ analysis. Temperature profile takes parabolic shape in 3D modeling. But in the region from centre of fluid to outer surface of riser pipe, the temperature distribution of 2D analysis doesn't reflect actual concept of FPSC at all. Along top length and along bottom length the temperature distribution of FPSC are depicted in the figure 17(iii)-(iv). From this figure it is observed that temperatures along the top and the bottom surface of FPSC are higher in 3D simulation than 2D simulation. there is a big difference between results of $3 \mathrm{D}$ and $2 \mathrm{D}$ modeling. This difference is not expected.

This can be explained in this way that in 3D computation the whole riser pipe becomes hot by conductive heat transfer process with absorber. Then cold fluids enter the riser pipe, collect heat from whole solid pipe surface, become hot and finally more heated output fluids are obtained. But in 2D computation only the top boundary of riser pipe becomes hot by conductive heat transfer process with absorber. There is no way to transfer heat by conduction from absorber to bottom boundary of riser pipe. Thus bottom boundary of pipe doesn't become hot. Then cold fluids enter the riser pipe, collect heat from top solid boundary of pipe and become hot. But at the same time cold bottom boundary of riser pipe tries to collect heat from hot fluids. Thus finally less heated output fluids are obtained than 3D computation. That's why 3D numerical analysis represents accurate heat transfer phenomena of FPSC.

\section{CONCLUSIONS}

Thermal behavior of fluids on forced convective boundary layer flow is accounted through a solar flat plate collector both in 2D and 3D simulations. Importance of 3D numerical simulation is explained showing differences in terms of various comparisons. Following conclusions have been drawn from the results of the numerical analysis:

- Mean subdomain velocity decreases by $18 \%$ using nanofluid than water in 3D simulation.

- Water/Cu nanofluid enhances thermal efficiency about $8 \%$ in $3 \mathrm{D}$ simulation.

- $17 \%$ heat transfer rate is obtained for increasing $\phi$ from $0 \%$ to $3 \%$ in $3 \mathrm{D}$ simulation.

- More heat transfer rate of about 3\% is obtained in 3D simulation than $2 \mathrm{D}$.

- In 3D simulation mean outlet temperature of water increases about $1.4 \mathrm{~K}$ than $2 \mathrm{D}$.

- Collector efficiency increases about 5\% in 3D simulation than $2 \mathrm{D}$.

\section{REFERENCES}

[1] Sukhatme, S. P., "Solar energy, principles of thermal collection and storage," New Delhi, Tata McGrawHill, 1991.

[2] Soltau, H., "Testing the thermal performance of uncovered solar collectors," Solar Energy, vol. 49, no. 4, pp. 263-272, 1992.

[3] Tripanagnostopoulos, Y., Souliotis, M., Nousia, T. H., "Solar collectors with colored absorbers," Solar Energy, vol. 68, pp. 343-356, 2000.
[4] Wazwaz, J., Salmi, H., Hallak, R., "Solar thermal performance of a nickel-pigmented aluminium oxide selective absorber," Renewable Energy, vol. 27, pp. 277-292, 2002.

[5] Piao, Y., Hauptmann, E. G. and Iqbal, M., "Forced convective heat transfer in cross-corrugated solar air heaters," ASME Journal of Solar Energy Engg., vol. 116, pp. 212-214, 1994.

[6] Gao, W., "Analysis and performance of a solar air heater with cross corrugated absorber and back-plate," MS thesis, Yunnan Normal University, Kunming, 1996.

[7] Konttinen, P., Lund, P. D. and Kilpi, R. J., "Mechanically manufactured selective solar absorber surfaces," Solar Energy Mater. Solar Cells, vol. 79, no. 3, pp. 273-283, 2003.

[8] Xiaowu, W. and Hua, B., "Energy analysis of domestic-scale solar water heaters," Renew. Sustain Energy Rev., vol. 9, no. 6, pp. 638-645, 2005.

[9] Hussain, "The performance of a cylindrical solar water heater," Renew. Energy, vol. 31, no. 11, pp. 17511763, 2006.

[10] Varol, Y. and Oztop, H. F., "Buoyancy induced heat transfer and fluid flow inside a tilled wavy solar collector," Building Environment, vol. 42, pp. 20622071, 2007

[11] Bég, O. A., Bakier, A., Prasad, R. and Ghosh, S. K., "Numerical modelling of non-similar mixed convection heat and species transfer along an inclined solar energy collector surface with cross diffusion effects," World J. of Mech., vol. 1, pp. 185-196, 2011.

[12] Nasrin, R. and Alim, M. A., "Finite element simulation of forced convection in a flat plate solar collector: Influence of nanofluid with double nanoparticles," $J$. of Appl. Fluid Mech., vol. 7, no. 3, pp. 543-557, 2014.

[13] Parvin, S., Nasrin, R. and Alim, M.A., "Heat transfer and entropy generation through nanofluid filled direct absorption solar collector," Int. J. of Heat and Mass Transf., vol. 71, pp. 386-395, 2014.

[14] Nasrin, R. and Alim, M. A., "Semi-empirical relation for forced convective analysis through a solar collector," Solar Energy, vol. 105, pp. 455-467, 2014.

[15] Nasrin, R. and Alim, M. A., "Modeling of a solar water collector with water based nanofluid using nanoparticles," Heat Trans.-Asian Res., vol. 43, no. 3, pp. 270-287, 2014.

[16] Nasrin, R., Parvin, S. and Alim, M. A., "Heat transfer and collector efficiency through direct absorption solar collector with radiative heat flux effect," Num. Heat Transf. Part A-Appl., vol. 68, No. 8, pp. 887-905, 2015.

[17] Nasrin, R. and Alim, M. A., "Dufour-Soret effects on buoyant convection through a nanofluid with different nanoparticles-filled solar collector", International Journal of Heat \& Technology, vol. 31, no. 1, pp. 3140, 2013.

[18] Nasrin, R. and Alim, M. A., "Thermal performance of nanofluid filled solar flat plate collector", International Journal of Heat \& Technology, vol. 33, no. 1, pp. 17-24, 2015.

[19] Nasrin, R., "Numerical analysis through a tubular reactor: velocity effect," International Journal of Heat \& Technology, vol. 34, no. 1, pp. 57-64, March 2016.

[20] Strukmann, F., "Analysis of a flat-plate solar collector," Project Report, 2008 MVK160, Heat and Mass Transport, Lund, Sweden, May 08, 2008. 
[21] Kalogirou, S. A., "Solar thermal collectors and applications," Progress in Energy and Combustion Sci., vol., 30, 231-295, 2004.

[22] E.R.F. Winter, Kolb and Viskanta, R., "Experimental studies on a solar air collector with metal matrix absorber," Solar Energy, vol. 65, no. 2, pp. 91-98, 1999.

[23] Martín, R. H., Pinar, A. G. and García, J. P., "Experimental heat transfer research in enhanced flatplate solar collectors," World Renew. Energy Cong., Solar Thermal Appli., Sweden, 2011.

[24] Azad, E., "Interconnected heat pipe solar collector," IJE Transactions A: Basic, vol. 22, No. 3, pp. 233242, 2009.

[25] Tagliafico, I. A., Scarpa, F. and Rosa, M. D., "Dynamic thermal models and CFD analysis for flatplate thermal solar collectors - a review," Renew. and Sust. Energy Rev., vol. 2, no. 30, pp. 526-537, 2014.

[26] Manjunath, M. S., Karanth, K. V. and Sharma, N. Y., "Three dimensional numerical analysis of conjugate heat transfer for enhancement of thermal performance using finned tubes in an economical unglazed solar flat plate collector," Proc. of the World Cong. on Engg., London, U.K., III, 2011.

[27] Karanth, K. V., Manjunath, M. S. and Sharma, N. Y., "Numerical simulation of a solar flat plate collector using discrete transfer radiation model (DTRM) - a CFD approach," Proc. of the World Cong. on Engg., London, U.K., III, 2011.

[28] Vestlund, J., "Gas-filled flat plate solar collector," $P h$. D. Thesis, Building Services Engg., Dept. of Energy and Environ., Chalmers University of Technology, Gothenburg, Sweden, 2012.

[29] Manjunath, M. S., Karanth, K. V. and Sharma, N. Y., "A comparative CFD study on solar dimple plate collector with flat plate collector to augment the thermal performance," World Academy of Sci., Engg. and Tech., vol. 6, pp. 10-21, 2012.

[30] Ingle, P. W., Pawar, A. A., Deshmukh, B. D., Bhosale, K. C., "CFD analysis of solar flat plate collector," Int. J. of Emerg. Techn. and Adv. Engg., vol. 3, no. 4, pp. 337-342, 2013.

[31] Basavanna, S. and Shashishekar, K. S., "CFD analysis of triangular absorber tube of a solar flat plate collector," Int. J. Mech. Eng. \& Rob. Res., vol. 2, no. 1, pp. 19-24, 2013.

[32] Brinkman, H. C., "The viscosity of concentrated suspensions and solution," J. Chem. Phys., vol. 20, 571-581, 1952.

[33] Maxwell-Garnett, J. C., "Colours in metal glasses and in metallic films," Philos. Trans. Roy. Soc. A, vol. 203, pp. 385-420, 1904.

[34] Taylor, C., Hood, P., "A numerical solution of the Navier-Stokes equations using finite element technique," Computer and Fluids, vol. 1, pp. 73-89, 1973.

[35] Dechaumphai, P., "Finite Element Method in Engineering," 2nd ed., Chulalongkorn University Press, Bangkok, 1999.

[36] Zienkiewicz, O. C and Taylor, R. L., "The finite element method," Fourth Ed., McGraw-Hill, 1991.

\section{NOMENCLATURES}

A aperature area of solar collector $\left(\mathrm{m}^{2}\right)$

$C_{p} \quad$ specific heat at constant pressure $\left(\mathrm{Jkg}^{-1} \mathrm{~K}^{-1}\right)$

$h$ convective heat transfer coefficient $\left(W^{-2} K^{-1}\right)$

I solar irradiation $\left(W^{-2}\right)$

$k \quad$ thermal conductivity of fluid $\left(W m^{-1} K^{-1}\right)$

$\mathrm{Nu} \quad$ average Nusselt number

p pressure $\left(\mathrm{kgms}^{-2}\right)$

$\mathrm{Pr} \quad$ Prandtl number

$q \quad$ heat flux $\left(W^{-2}\right)$

$T \quad$ fluid temperature $(K)$

$u, v, w \quad$ velocity components along $\mathrm{x}, \mathrm{y}, \mathrm{z}$ direction $\left(m s^{-1}\right)$

$U_{l} \quad$ overall heat transfer coefficient $\left(W^{-2} K^{-l}\right)$

$\mathrm{V}$ magnitude of velocity

$V \quad$ volume of riser pipe $\left(m^{3}\right)$

$x, y, z \quad$ Cartesian coordinates $(m)$

$X, Y, Z \quad$ dimensionless Cartesian coordinates

\section{Greek symbols}

$\begin{array}{ll}\alpha & \text { thermal diffusivity }\left(\mathrm{m}^{2} \mathrm{~s}^{-1}\right) \\ \alpha & \text { absorptyivity } \\ \tau & \text { transmitivity } \\ \eta & \text { thermal efficiency } \\ \phi & \text { nanoparticles volume fraction } \\ \theta & \text { dimensionless fluid temperature } \\ \mu & \text { dynamic viscosity of the fluid }\left(\mathrm{m}^{2} \mathrm{~s}^{-1}\right) \\ v & \text { kinematic viscosity of the fluid }\left(\mathrm{m}^{2} \mathrm{~s}^{-1}\right) \\ \rho & \text { density of the fluid }\left(\mathrm{kgm}^{-3}\right)\end{array}$

\section{Subscripts}

$\begin{array}{ll}a & \text { absorber } \\ \text { amb } & \text { ambient } \\ a v & \text { average } \\ \text { col } & \text { collector } \\ f & \text { fluid } \\ \text { in } & \text { input } \\ \text { loss } & \text { lost } \\ n f & \text { nanofluid } \\ \text { out } & \text { output } \\ \text { recv } & \text { received } \\ \text { s } & \text { solid particle } \\ \text { usfl } & \text { useful }\end{array}$

